Argonne National Laboratory

9700 South Cass Avenue

Argonne, Illinois 60439

ROCKING RESPONSE OF TANKS

CONTAINING TWO LIQUIDS

by

Yu Tang and Y. W. Chang

Reactor Engineering Division

June 1993

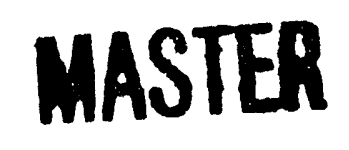

Se 
ABSTRACT $\ldots \ldots \ldots \ldots \ldots \ldots \ldots \ldots \ldots \ldots \ldots \ldots \ldots \ldots \ldots \ldots \ldots \ldots \ldots \ldots$

I. INTRODUCTION $\ldots \ldots \ldots \ldots \ldots \ldots \ldots \ldots \ldots \ldots \ldots \ldots \ldots \ldots$

II. SYSTEM DESCRIPTION $\ldots \ldots \ldots \ldots \ldots \ldots \ldots \ldots \ldots \ldots \ldots \ldots \ldots$

III. GOVERNING EQUATIONS AND BOUNDARY CONDITIONS ........ 3

IV. PRESENTATION OF RESULTS $\ldots \ldots \ldots \ldots \ldots \ldots \ldots \ldots \ldots \ldots$

A. Impulsive Component of Hydrodynamic Pressure $\ldots \ldots \ldots \ldots \ldots 7$

B. Impulsive Component of Base Shear $\ldots \ldots \ldots \ldots \ldots \ldots \ldots \ldots$

C. Impulsive Components of Base Moments . . . . . . . . . 10

D. Convective Component of Hydrodynamic Pressure $\ldots \ldots \ldots \ldots \ldots$

E. Convective Component of Base Shear ............... 12

F. Convective Components of Base Moment $\ldots \ldots \ldots \ldots \ldots \ldots$

G. Surface and Interface Sloshing Displacements $\ldots \ldots \ldots \ldots \ldots$

V. CONCLUSIONS $\ldots \ldots \ldots \ldots \ldots \ldots \ldots \ldots \ldots \ldots \ldots \ldots \ldots \ldots \ldots \ldots$

ACKNOWLEDGMENTS $\ldots \ldots \ldots \ldots \ldots \ldots \ldots \ldots \ldots \ldots \ldots \ldots \ldots \ldots$

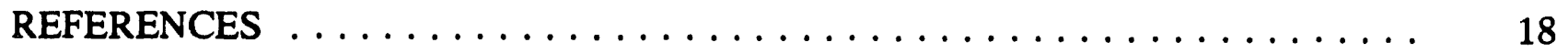

APPENDIX A. SOLUTION FOR RIGID TANKS $\ldots \ldots \ldots \ldots \ldots \ldots \ldots$ A-1 


\section{LIST OF TABLES}

No.

Title

Page

I Quantities in Expressions for the Impulsive Components of

Response for $\mathrm{H}_{2} / \mathrm{H}_{1}=0.5 \ldots \ldots \ldots \ldots \ldots \ldots \ldots \ldots \ldots$

II Quantities in Expressions for the Impulsive Components of

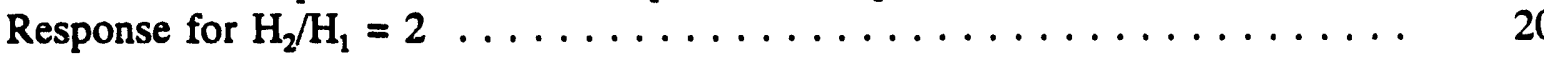




\section{LIST OF FIGURES}

No.

Title

$\underline{\text { Page }}$

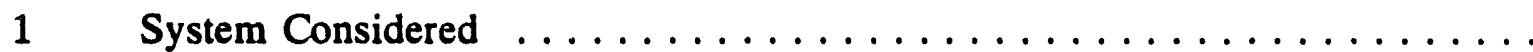

2 Impulsive Pressure Exerted on Tank Wall for $\mathrm{H}_{2} / \mathrm{H}_{1}=0.5 \ldots \ldots \ldots \ldots 22$

3 Impulsive Pressure Exerted on Tank Wall for $\mathrm{H}_{2} / \mathrm{H}_{1}=2 \ldots \ldots \ldots \ldots 22$

4 Effect of Mass Densities on Impulsive Component of Base

Moment ............................. 23

5 Effect of Mass Densities on Impulsive Component of Base

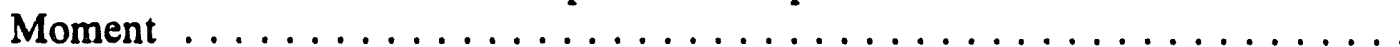




\title{
ROCKING RESPONSE OF TANKS \\ CONTAINING TWO LIQUIDS
}

by

Yu Tang and Y. W. Chang

\begin{abstract}
A study on the dynamic response of upright circular cylindrical liquid-storage tanks containing two different liquids under a rocking base motion with an arbitrary temporal variation is presented. Only rigid tanks were studied. The response quantities examined include the hydrodynamic pressure, sloshing wave height and the associated frequencies, base shear and moments. Each of these response quantities is expressed as the sum of the so-called impulsive component and convective component. Unlike the case of tanks containing one liquid, in which the response is controlled by one parameter, height-to-radius ratio, the response of tanks containing two different liquids are controlled by three parameters: height-to-radius ratio, and mass density ratio and height ratio of the two liquids. The interrelationship of the responses of the tank-liquid system to rocking and lateral base excitations is established by examining numerical results extensively. It is found that some of the response quantities for a tank-liquid system under a rocking base motion can be determined from the corresponding response quantities for an identical tank under a horizontal base motion.
\end{abstract}




\section{INTRODUCTION}

Liquid storage tanks are important components of industrial facilities and, when located in earthquake prone regions, should be designed to withstand the earthquakes to which they may be subjected. The dynamic response of liquid-storage tanks subjected to earthquakes has been a subject of numerous studies in the past 30 years. For reviews of the previous studies on responses of laterally, vertically and rockingly excited tank-liquid systems the reader is referred to the papers of Veletsos [1], Veletsos and Tang [2] and Veletsos and Tang [3], respectively. Most of the previous studies were focused on the tank containing only one liquid. However, there are cases in which the density of the tank content is not uniform. For such cases, the dynamic responses of tanks containing liquids with different densities must be studied. To respond to this need, Tang [4] presented a solution for dynamic response of rigid tanks containing two liquids under a horizontal base motion. In that study, however, the effect of the gravitation on the interface motion of two liquids was neglected. It should be mentioned that this gravitational effect was later considered in the analysis and the findings are described in detail in an ANL/RE report [5]. The dynamic characteristics of the flexible tarks containing two liquid was studied by Tang [6]. All these studies are aimed at the understanding of the dynamic behavior of tanks containing two liquids under lateral base motions. This report describes the dynamic response of tanks containing two liquids of different densities under rocking base motions. It should be noted that base rocking motion can occur in a ground-supported tank or in an elevated tank under earthquake motions. Due to the flexibility of either the supporting soil or the supporting tower, the tank base will experience a rocking component of motion, even for a purely translational free field motion.

The objectives of this paper are: (1) to present the exact solution for the dynamic response of tanks containing two liquids under base rocking motions; (2) to elucidate the interrelationship of the responses of a tank to rocking and lateral base motions; and (3) to provide a foundation for the study of the soil-structure interaction analysis of tanks containing two liquids. The response functions examined are the hydrodynamic pressure, the sloshing motion and the associated natural frequencies, the base shear and moments. Fiow to utilize these response functions in the tank design can be found in Ref. 1. In this report, each of these response functions is expressed as the sum of the so-called impulsive and convective components of the 
response. This division is necessary because it is essential to the approach used in Refs. 6, 7 and 8 for the analysis of flexible tanks. The impulsive component of the response represents the effects of the part of the liquid that moves in unison with the tank, whereas the convective component represents the effects of the part of the liquid that associates with the sloshing motion.

In this report, the interrelationship of the responses of a tank containing two liquids under base rocking motion and under base horizontal motion is established by examining numerical data of the response functions under the two base motions extensively. It is found, similar to the case of the responses of tanks containing one liquid, that for tanks containing two liquids some of the response quantities may be evaluated from the existing data for the same tank-liquid system under lateral excitations. Similar to the response of tanks containing two liquids under horizontal base motions presented in Ref. 5, a tank containing two liquids under a base rocking motion has two natural frequencies associated with each sloshing mode of vibration. These natural frequencies are the same as those for tanks in lateral excitation.

\section{SYSTEM DESCRIPTION}

The tank-liquids system investigated is shown in Fig. 1. It is a ground-supported upright circular cylindrical tank of radius $R$ that is filled with two liquids to a total height of $H$. The lower portion liquid, identified as Liquid $\mathrm{I}$, has heavier mass density, $\rho_{1}$, and the upper portion liquid, identified as Liquid II, has lighter mass density, $\rho_{2}$. The heights of Liquid I and II are $\mathrm{H}_{1}$ and $\mathrm{H}_{2}$, respectively. The tank wall is assumed to be of uniform thickness and clamped to a rigid base. Both liquids are considered to be incompressible and inviscid. The response of the liquids is assumed to be linear.

Let $r, \theta, z_{1}$ denote the radial, circumferential, and vertical axial coordinates of a point in the Liquid $I$, and let $r, \theta$, and $z_{2}$ be the corresponding coordinates for a point in Liquid II as shown in Fig. 1. The origins of the two coordinate systems are at the central axis of the cylindrical tank.

The base motion experienced by the tank is an angular acceleration, denoted by $\ddot{\theta}_{b}(t)$, acting in the direction along the $\theta=90^{\circ}$ coordinate axis. The temporal variation of $\ddot{\theta}_{b}(t)$ can be arbitrary. 


\section{GOVERNING EQUATIONS AND BOUNDARY CONDITIONS}

Given the conditions that the liquids are incompressible and inviscid, the hydrodynamic pressures induced at Liquid $I$ and Liquid II, denoted by $p_{1}$ and $p_{2}$ respectively, must satisfy the Laplace equations

$$
\nabla^{2} \mathrm{p}_{1}=0
$$

in the region $0 \leq r \leq R, 0 \leq \theta \leq 2 \pi$, and $0 \leq z_{1} \leq H_{1}$, and

$$
\nabla^{2} \mathrm{p}_{2}=0
$$

in the region $0 \leq r \leq R, 0 \leq \theta \leq 2 \pi$, and $0 \leq \mathrm{z}_{2} \leq \mathrm{H}_{2}$.

The liquid acceleration at an arbitrary point along $\mathrm{n}$-direction is given by

$$
a_{n}=-\frac{1}{\rho_{1}} \frac{\partial p_{1}}{\partial n}
$$

for points in Liquid I, and

$$
a_{n}=-\frac{1}{\rho_{2}} \frac{\partial p_{2}}{\partial n}
$$

for points in Liquid II.

The boundary conditions for Liquid I are:

(a) The vertical acceleration of Liquid I at the tank base must equal the acceleration of the base plate, i.e.,

$$
-\left.\frac{1}{\rho_{1}} \frac{\partial p_{1}}{\partial z_{1}}\right|_{z_{1}=0}=r \cos \theta \ddot{\theta}_{b}(t)
$$

(b) The radial acceleration of Liquid I adjacent to the tank wall must equal the acceleration of the tank wall, i.e.,

$$
-\left.\frac{1}{\rho_{1}} \frac{\partial p_{1}}{\partial r}\right|_{r=R}=-z_{1} \cos \theta \ddot{\theta}_{b}(t) \text {, and }
$$

The boundary conditions for Liquid II are: 
(a) The radial acceleration along the tank wall is given by

$$
-\left.\frac{1}{\rho_{2}} \frac{\partial p_{2}}{\partial r}\right|_{r=R}=-\left(z_{2}+H_{1}\right) \cos \theta \ddot{\theta}_{b}(t),
$$

(b) At free surface, the linearized boundary condition is

$$
\left(\frac{\partial^{2} p_{2}}{\partial t^{2}}+g \frac{\partial p_{2}}{\partial z_{2}}\right)_{z_{2}=H_{2}}=0
$$

where $\mathrm{g}$ is the gravitational acceleration, and

The boundary conditions at the interface of two liquids are as follows.

(a) Continuity of vertical accelerations, i.e.,

$$
-\left.\frac{1}{\rho_{1}} \frac{\partial p_{1}}{\partial z_{1}}\right|_{z_{1}=H_{1}}=-\left.\frac{1}{p_{2}} \frac{\partial p_{2}}{\partial z_{2}}\right|_{z_{2}=0}
$$

and

(b) Kinematic and pressure conditions:

b.1 Kinematic condition. If $\eta(r, \theta, t)$ represents the height of the small disturbance at the interface above the still interface level, the $\eta(r, \theta, t)$ is related to $p_{1}$ by

$$
\frac{\partial^{2} \eta}{\partial t^{2}}=-\left.\frac{1}{\rho_{1}} \frac{\partial p_{1}}{\partial z_{1}}\right|_{z_{1}=H_{1}}
$$

b.2 Pressure condition. If the gravitational effect is considered for the interface motion, there is a discontinuity of the hydrodynamic pressure with the amount of $\left(\rho_{1}-\rho_{2}\right) g \eta$ at the interface, i.e.,

$$
\left.p_{1}\right|_{z_{1}=H_{1}}-\left.p_{2}\right|_{z_{2}=0}=\left(\rho_{1}-\rho_{2}\right) g \eta
$$

Eliminating $\eta$ between Eqs. (5) and (6) and making use of the Eq. (4e), one obtains the following equation for the interface boundary conditions in addition to Eq. (4e). 


$$
\left.\left(\frac{\partial^{2} p_{1}}{\partial t^{2}}+g \frac{\partial p_{1}}{\partial z_{1}}\right)\right|_{z_{1}=H_{1}}=\left.\left(\frac{\partial^{2} p_{2}}{\partial t^{2}}+g \frac{\partial p_{2}}{\partial z_{2}}\right)\right|_{z_{2}=0}
$$

Also,

$\mathrm{p}_{1}$ and $\mathrm{p}_{2}$ are finite at $\mathrm{r}=0$

The solutions for $p_{1}$ and $p_{2}$ are expressed as the sum of the impulsive component and convective component, i.e.,

$$
p_{1}=p_{1}^{i r}+p_{2}^{c r}
$$

and

$$
\mathrm{p}_{2}=\mathrm{p}_{2}^{\mathrm{ir}}+\mathrm{p}_{2}^{\mathrm{cr}}
$$

where the superscript $i=$ impulsive component; the superscript $c=$ convective component; and the superscript $r$ is used as a reminder for rocking.

The detailed derivation of these solutions are given in Appendix A. The solutions for these functions are summarized as follows.

$$
\begin{aligned}
& p_{1}^{\text {ir }}\left(r, \theta, z_{1}, t\right)=C_{o}^{i r}\left(r, z_{1}\right) \ddot{x}_{T}(t) \rho_{1} R \cos \theta \\
& p_{2}^{\text {ir }}\left(r, \theta, z_{2}, t\right)=C_{0}^{\text {IIr }}\left(r, z_{2}\right) \ddot{x}_{T}(t) \rho_{2} R \cos \theta \\
& p_{1}^{\text {cr }}\left(r, \theta, z_{1}, t\right)=\left[\sum_{n=1}^{\infty} \sum_{k=1}^{2} C_{n k}^{\text {Ir }}\left(r, z_{1}\right) A_{n k}^{r}(t)\right] \rho_{1} R \cos \theta
\end{aligned}
$$

and

$$
\mathrm{p}_{2}^{\mathrm{ct}}\left(\mathrm{r}, \theta, \mathrm{z}_{2}, \mathrm{t}\right)=\left[\sum_{\mathrm{n}=1}^{\infty} \sum_{\mathrm{k}=1}^{2} \mathrm{C}_{n k}^{\mathrm{IIr}}\left(\mathrm{r}, \mathrm{z}_{2}\right) A_{n k}^{\mathrm{r}}(\mathrm{t})\right] \rho_{2} R \cos \theta
$$

where superscripts I and II denote Liquids I and II, respectively. The expressions for dimensionless functions $C_{o}^{\mathrm{Ir}}\left(r, z_{1}\right), C_{o}^{\mathrm{llr}}\left(r, z_{2}\right), C_{n k}^{\mathrm{lr}}\left(r, z_{1}\right)$ and $C_{n k}^{\mathrm{llr}}\left(r, z_{2}\right)$ are given in Appendix $A ; \ddot{x}_{T}(t)$ $=H \ddot{\theta}_{b}(t)=$ the horizontal acceleration of the tank wall at the level of the still liquid surface, and 
the functions $A_{n k}{ }^{r}(t), k=1$ and 2 are the pseudoacceleration functions for the $n$th sloshing mode of vibration, $J_{1}\left(\lambda_{\mathrm{a}} \frac{r}{R}\right)$, and are defined by

$$
A_{n k}^{r}(t)=\omega_{n k} \int_{0}^{t} \ddot{x}_{T}(t) \sin \left(\omega_{n k}(t-\tau)\right) d \tau
$$

in which $\omega_{\mathrm{nk}}, \mathrm{k}=1,2,=$ the natural frequencies associated with the nth sloshing mode of vibration. Note that for the nth sloshing mode of vibration there are two natural frequencies, $\omega_{n 1}$ and $\omega_{n 2}$. This phenomena has been discussed in Ref. 5. Introducing the notation, $\Lambda_{n k}$, for a nondimensional coefficient that is related to $\omega_{\mathrm{nk}}$ by the equation

$$
\Lambda_{\mathrm{nk}}=\frac{\omega_{\mathrm{nk}}^{2} R}{\lambda_{\mathrm{n}} \mathrm{g}}
$$

It is shown in Appendix $A$ that $\Lambda_{n k}, k=1,2$, are the roots of the characteristic equation given by

$$
a \Lambda_{n}^{2}-b \Lambda_{n}+c=0
$$

where

$$
\begin{aligned}
& a=1+\alpha \tanh \beta_{1 \mathrm{n}} \tanh \beta_{2 \mathrm{n}} \\
& \mathrm{b}=\tanh \beta_{1 \mathrm{n}}+\tanh \beta_{2 \mathrm{n}}
\end{aligned}
$$

and

$$
c=(1-\alpha) \tanh \beta_{1 \mathrm{n}} \tanh \beta_{2 \mathrm{n}}
$$

in which $\beta_{1 \mathrm{n}}=\lambda_{\mathrm{n}} \frac{\mathrm{H}_{1}}{\mathrm{R}}, \beta_{2 \mathrm{n}}=\lambda_{\mathrm{n}} \frac{\mathrm{H}_{2}}{\mathrm{R}}$ and $\alpha=\rho_{2} / \rho_{1}$.

It can be shown that the discriminant of Eq. (15) $D=b^{2}-4 a c>0$ for $\alpha>0$; therefore, Eq. (15) has two real and unequal roots. Explicitly, these two roots are given by

$$
\Lambda_{\mathrm{n} 1}=\frac{b+\sqrt{D}}{2 a}
$$

and 


$$
\Lambda_{n 2}=\frac{b-\sqrt{D}}{2 a}
$$

Obviously, $\Lambda_{\mathrm{n} 1}>\Lambda_{\mathrm{n} 2}$; hence $\omega_{\mathrm{n} 1}>\omega_{\mathrm{n} 2}$. The reasons for this reverse order numbering for the natural frequencies were explained in Ref. 5. Note that, the Eq. (15) is identical to the characteristic equation presented in Ref. 5 for tanks subjected to a lateral base motion, i.e., the natural frequencies for the sloshing motion in a tank undergoing rocking motion are the same as those of the sloshing motion in an identical tank subjected to a lateral excitation. The numerical results for values of $\omega_{\mathrm{nk}}$ are available in Ref. 5 .

\section{PRESENTATION OF RESULTS}

The dynamic response of a tank containing two liquids under rocking base excitations is controlled by three parameters, $\mathrm{H} / \mathrm{R}, \mathrm{H}_{2} / \mathrm{H}_{1}$ and $\alpha$, which are the same control parameters as those for the dynamic response of a tank containing two liquids under lateral base excitations.

\section{A. Impulsive Component of Hydrodynamic Pressure}

The impulsive pressure exerted on the tank wall is conveniently expressed in the form

$$
\mathrm{p}^{\mathrm{ir}}(\theta, z, t)=\mathrm{C}_{0}^{\mathrm{r}}(\mathrm{z}) \ddot{x}_{\mathrm{T}}(\mathrm{t}) \rho_{1} R \cos \theta
$$

where $C_{0}{ }^{r}(z)$ is given by

$$
\begin{aligned}
& C_{0}^{r}(z)=\left.C_{0}^{\mathrm{Ir}}\left(r, z_{1}\right)\right|_{r=R} \quad \text { for } 0 \leq z \leq H_{1} \\
& C_{0}^{r}(z)=\left.\alpha C_{0}^{I I r}\left(r, z_{2}\right)\right|_{z=R} \quad \text { for } H_{1} \leq z \leq H
\end{aligned}
$$

The coordinate $z$ used in Eq. (19) is related to $z_{1}$ and $z_{2}$ by the equations

$$
z=z_{1} \quad \text { for } 0 \leq z \leq H_{1}
$$

and

$$
z=z_{2}+H_{1} \quad \text { for } H_{1} \leq z \leq H
$$


It is clearly shown in Eq. (19) that the timewise variation of the impulsive pressure is the same as that of the base excitation. This indicates that the impulsive pressure is produced by a portion of liquid that moves in unison with the tank wall.

The distributions of $C_{0}{ }^{r}(z)$ for $\alpha=0.25,0.5,0.75$ and 1 for a broad tank, $H / R=0.5$, and a tall tank, $H / R=3$ are shown in Fig. 2 for $\mathrm{H}_{2} / \mathrm{H}_{1}=0.5$ and in Fig. 3 for $\mathrm{H}_{2} / \mathrm{H}_{1}=2$. Note that for a broad tank, the impulsive pressure decreases monotonically from bottom to top, whereas for a tall tank the shape of impulsive pressure distribution has a double curvature. The maximum value occurs at a point away from the bottom. These trends are in agreement with those presented in Ref. 3 for tanks containing one liquid undergoing rocking motion. The impulsive pressure decreases as the value of $\alpha$ decreases. This reduction is more pronounced in tall tanks and for larger values of $\mathrm{H}_{2} / \mathrm{H}_{1}$.

B. Impulsive Component of Base Shear

The impulsive component of base shear, $Q^{i r}(t)$, is given by

$$
\begin{aligned}
Q^{i r}(t) & =\left.\int_{0}^{2 \pi} \int_{0}^{H_{1}} p_{1}^{i r}\right|_{r=R} R \cos \theta d z_{1} d \theta \\
& +\left.\int_{0}^{2 \pi} \int_{0}^{H_{1}} p_{2}^{i t}\right|_{r=R} R \cos \theta d z_{2} d \theta
\end{aligned}
$$

Substituting Eqs. (9) and (10) into Eq. (22) and performing the integration, one obtains the expression for $Q^{\text {ir }}(t)$ which is given as

$$
Q^{i r}(t)=S_{0}^{l t} M_{11} \ddot{x}_{\tau}(t)+S_{0}^{l l t} M_{12} \ddot{x}_{\tau}(t)
$$

in which $M_{n}=\rho_{1} \pi R^{2} H_{1}=$ total liquid mass of liquid $I ; M_{n}=\rho_{2} \pi R^{2} H_{2}=$ total mass of liquid Il; and $S_{0}^{I t}$ and $S_{0}^{I I r}=$ dimensionless coefficients dependent on the values of $H / R, H_{2} / H_{1}$ and $\alpha$.

In Eq. (23), the first term on the right-hand side is the base shear contributed from Liquid I, and the second term is from Liquid II. Since Eq. (22) involves only simple integrations of hyperbolic functions, the expressions for $S_{0}^{\text {It }}$ and $S_{0}^{\text {Ilt }}$ are not given herein. The expression given 
by Eq. (23) has a physical meaning; it gives the volume ratio of each liquid that may be considered as added mass to the tank wall. However, to study the effect of two liquids on the total base shear, it is also desirous to have an expression that can be used for comparison with an identical tank that contains one liquid. Therefore, $Q^{\text {ir }}(t)$ is also expressed as

$$
Q^{\text {ir }}(t)=r_{0 s}^{i r} M_{t}^{1} \ddot{x}_{T}(t)
$$

in which $M_{1}{ }^{1}=\pi \rho_{1} R^{2} H=$ the total liquid mass if the tank is filled with Liquid $I$; and $r_{0 s}^{i r}=$ dimensionless coefficient related to $S_{0}^{\text {It }}$ and $S_{0}^{\text {IIr }}$ by the equation

$$
\mathrm{r}_{08}^{\mathrm{ir}}=\frac{\mathrm{S}_{0}^{\mathrm{Ir}} \mathrm{H}_{1}+\alpha \mathrm{S}_{0}^{\mathrm{IIt}} \mathrm{H}_{2}}{\mathrm{H}}
$$

The values of $S_{0}^{\text {It }}$ and $S_{0}^{I I t}$ for different control parameters, $H / R, H_{2} / H_{1}$ and $\alpha$, are listed in columns (1) and (2) of Tables I and II, from which one can see that for the same values of $H / R$ and $H_{2} / H_{1}$, the value of $S_{0}^{\text {Ir }}$ increases as the value of $\alpha$ increases, whereas the value of $S_{0}^{\text {ilt }}$ decreases with increasing value of $\alpha$.

Examination of the numerical value of $r_{08}^{i r}$ reveals that this quantity can be computed from the quantities in the expressions for the base moments of an identical tank-liquid system excited laterally. Specifically, for an identical system excited laterally by an acceleration of $\ddot{x}(t)$, the base moment $M^{i}(t)$ at a section immediately above the tank base can be expressed as

$$
M^{i}(t)=r_{0}^{i} M_{t}^{1} H \ddot{x}(t)
$$

and the base moment induced by the pressure exerted on the tank base, denoted by $\Delta M^{i}(t)$, is given by

$$
\Delta M^{\prime}(t)=\Delta r_{0 M}^{i} M_{l}^{1} H \ddot{x}(t)
$$

Then, it is found that the value of $r_{03}^{i r}$ is related to the values of $r_{0 M}^{i}$ and $\Delta r_{0 M}^{i}$ by the equation

$$
r_{0 s}^{i r}=r_{0 M}^{i}+\Delta r_{0 M}^{i}
$$


The relation defined by Eq. (28) may be explained by a generalization of Betti's principle stated in Ref. 3. In that paper, the same relation as that defined by Eq. (28) is found for tank containing one liquid inder rocking motion. Numerical values for $r_{0 M}^{\prime}$ and $\Delta r_{0 M}^{\prime}$ have been given by Tang [4] and Tang and Chang [9]; therefore, the value of $r_{0,}^{r}$ may be computed by direct application of Eq. (28).

\section{Impulsive Components of Base Moments}

The base moment $M^{i x}(t)$ at a section immediately above the tank base is computed from

$$
\begin{aligned}
M^{\mathrm{ir}}(t) & =\left.\int_{0}^{2 \pi} \int_{0}^{H_{1}} p_{1}^{\mathrm{it}^{\mathrm{t}}}\right|_{\mathrm{r}=\mathrm{R}} R z_{1} \cos \theta d z_{1} d \theta \\
& +\left.\int_{0}^{2 \pi} \int_{0}^{H_{2}} p_{2}^{\mathrm{it}}\right|_{r=R} R\left(z_{2}+H_{1}\right) \cos \theta d z_{2} d \theta
\end{aligned}
$$

and the result is expressed as

$$
M^{\text {ir }}(t)=C_{0 M}^{\text {lr }} \ddot{x}_{T}(t) M_{11} H_{1}+C_{0 M}^{l l t r} \ddot{x}_{T}(t) M_{12} H_{2}
$$

Again, since Eq. (29) involves only the simple integrations of hyperbolic functions, the expressions for $C_{0 M}^{\mathrm{lr}}$ and $\mathrm{C}_{0 \mathrm{M}}^{\mathrm{llt}}$ are not given herein.

The numerical values of $\mathrm{C}_{0 \mathrm{M}}^{\mathrm{lr}}$ and $\mathrm{C}_{0 \mathrm{M}}^{\mathrm{II}}$ are listed in columns (3) and (4) of Tables I and II. For the same values of $H / R$ and $H_{2} / H_{1}$, the valuc $: f \mathrm{C}_{0 M}^{\text {tr }}$ increases as the value of $\alpha$ increases, but the value of $\mathrm{C}_{0 \mathrm{M}}^{\mathrm{IIr}}$ has an opposite trend.

Equation (30) is also rewritten as

$$
M^{i r}(t)=r_{0 M}^{i t} M_{t}{ }^{1} H \ddot{x}_{T}(t)
$$

in which $r_{0 M}^{i r}=a$ dimensionless coefficient defined by

$$
r_{0 M}^{\mathrm{ir}}=\mathrm{C}_{0 M}^{\mathrm{lr}}\left(\frac{\mathrm{H}_{1}}{\mathrm{H}}\right)^{2}+\alpha \mathrm{C}_{0 M}^{\mathrm{ll} r}\left(\frac{\mathrm{H}_{2}}{\mathrm{H}}\right)^{2}
$$


The value of $\mathrm{r}_{0 \mathrm{M}}^{\mathrm{ir}}$ is presented graphically in Fig. 4 for different values of $\mathrm{H}_{2} / \mathrm{H}_{1}$ as a function of $\alpha$. Four different values of $H / R$ are considered; they are $0.5,1,2$ and 3. From Fig. 4 it is noted that the value of $r_{0 M}^{i r}$ decreases with decreasing value of $\alpha$, and the decrease is more rapid for large values than for small values of $\mathrm{H}_{2} / \mathrm{H}_{1}$.

The base moment induced by the impulsive pressure exerted on the tank base is denoted by $\Delta M^{i r}(t)$ which is given by the following equation

$$
\Delta M^{i r}(t)=\left.\int_{0}^{2 \pi} \int_{0}^{R} p_{1}^{i r}\right|_{z_{1}=0} r^{2} \cos \theta d r d \theta
$$

and may be expressed in the form as

$$
\Delta M^{i r}(t)=\Delta C_{0 M}^{r} \ddot{x}_{T}(t) M_{11} H_{1}
$$

in which $\Delta \mathrm{C}_{0 \mathrm{M}}^{\mathrm{r}}=\mathrm{a}$ dimensionless coefficient. The value of $\Delta \mathrm{C}_{0 \mathrm{M}}^{\mathrm{r}}$ is tabulated in column (5) of Tables I and II. It shows that the value of $\Delta C_{0 M}^{r}$ decreases rapidly as the value of $H / R$ increases.

For the reason identified earlier, Eq. (34) is also expressed as

$$
\Delta M^{\mathrm{ir}}(\mathrm{t})=\Delta \mathrm{r}_{0 M}^{\mathrm{ir}} \ddot{x}_{\mathrm{T}}(\mathrm{t}) M_{1}^{1} H
$$

to compare the result with that corresponding to $\alpha=1$. The coefficient $\Delta \mathrm{r}_{0 M}^{\mathrm{r}}$ is related to $\Delta \mathrm{C}_{0 \mathrm{M}}^{\mathrm{r}}$ by the equation

$$
\Delta \mathrm{r}_{0 \mathrm{M}}^{\mathrm{ir}}=\Delta \mathrm{C}_{0 \mathrm{M}}^{\mathrm{r}}\left(\frac{\mathrm{H}_{1}}{\mathrm{H}}\right)^{2}
$$

The values of $\Delta r_{0 M}^{i r}$ are shown in Fig. 5. It can be seen that for a tall tank this moment is much smaller than that for a broad tank. Note that in Fig. 5 , the vertical scale for $H / R=1$ is one-fifth of that for $\mathrm{H} / \mathrm{R}=0.5$. 


\section{Convective Component of Hydrodynamic Pressure}

The convective pressure exerted on the tank wall may be obtained by evaluating the pressures defined by Eqs. (11) and (12) at $r=R$. This approach is similar to that used in obtaining the impulsive pressure exerted on the tank wall presented above. However, in this paper a physically motivated approach is used to derive the convective pressure instead, and the results obtained by the two approaches will be checked against each other.

Since the natural modes of vibration and the natural frequencies of the sloshing motion in a tank-liquid system are independent of the excitation that the system is experienced, the heightwise distribution of the convective hydrodynamic wall pressure induced by the rocking motion will be identical to that induced by the lateral motion. If the heightwise distribution of the convective component of the hydrodynamic pressure under lateral excitation is given by the function $C_{n k}(z)$, then, following from the above argument, the convective pressure, $p^{c r}(z, \theta, t)$, under rocking can be expressed as

$$
\mathrm{p}^{\mathrm{cr}}(\mathrm{z}, \theta, \mathrm{t})=\left[\sum_{n=1}^{\infty} \sum_{k=1}^{2} \gamma_{n k} C_{n k}(z) A_{n k}^{r}(t)\right] \rho_{1} R \cos \theta
$$

in which $\gamma_{\mathrm{nk}}=\mathrm{a}$ dimensioniess proportionality factor that remains to be determined.

\section{E. Convective Component of Base Shear}

It is shown in Ref. 5 that the convective base shear, $Q^{c}(t)$, for tank-liquid excited laterally is given by

$$
Q^{c}(t)=\left[\sum_{n=1}^{\infty} \sum_{k=1}^{2} S_{n k}^{\prime} A_{n k}(t)\right] M_{t 1}+\left[\sum_{n=1}^{\infty} \sum_{k=1}^{2} S_{n k}^{\prime \prime} A_{n k}(t)\right]
$$

or, it may be expressed differently as

$$
Q^{c}(t)=\left[\sum_{n=1}^{\infty} \sum_{k=1}^{2} r_{n k}^{*} A_{n k}(t)\right] M_{l}^{1}
$$


in which $A_{n k}(t)=$ the instantaneous pseudoacceleration induced by a base acceleration $\ddot{x}(t)$ in a SDF system of circular natural frequency $\omega_{n k} \cdot A_{n k}(t)$ is obtained from Eq. (13) by replacing $\ddot{x}_{T}(t)$ by $\ddot{x}(t)$. By application of the same analogy used in obtaining convective pressure, Eq. (37), for system in rocking motion from that for system in lateral motion, one obtains the convective base shear for system in rocking motion from Eqs. (38) which is given as

$$
\begin{aligned}
Q^{c r}(t) & =\left[\sum_{n=1}^{\infty} \sum_{k=1}^{2} \gamma_{n k} S_{n k}^{\mathrm{r}} A_{n k}^{r}(t)\right] M_{41} \\
& +\left[\sum_{n=1}^{\infty} \sum_{k=1}^{2} \gamma_{n k} S_{n k}^{n} A_{n k}^{r}(t)\right] M_{12}
\end{aligned}
$$

or from Eq. (39), one obtains

$$
Q^{\mathrm{cr}}(\mathfrak{t})=\left[\sum_{n=1}^{\infty} \sum_{k=1}^{2} \gamma_{n k} r_{n k}^{3} A_{n k}^{r}(t)\right] M_{1}^{1}
$$

Note that Eqs. (40) and (41) can also be obtained from Eq. (22) by replacing function $\mathrm{p}^{\mathrm{ir}}(\mathrm{t})$ by the function $p^{c c}(t)$ of Eq. (37) and performing the integrations.

\section{F. Convective Components of Base Moments}

It is shown in Ref. 5 that the convective base moment, $M^{c}(t)$, at a section immediately above the tank base for tank-liquid system excited laterally can be expressed as

$$
\begin{aligned}
M^{c}(t) & =\left[\sum_{n=1}^{\infty} \sum_{k=1}^{2} C_{n k}^{M I} A_{n k}(t)\right] M_{11} H_{1} \\
& +\left[\sum_{n=1}^{\infty} \sum_{k=1}^{2} C_{n k}^{M I I} A_{n k}(t)\right] M_{12} H_{2}
\end{aligned}
$$

and the base moment induced by the pressure exerted on the tank base, denoted by $\Delta \mathbf{M}^{\mathrm{c}}(\mathrm{t})$, is given by 


$$
\Delta M^{c}(t)=\left[\sum_{n=1}^{\infty} \sum_{k=1}^{z} \Delta C_{n k}^{M} A_{n k}(t)\right] M_{11} H_{1}
$$

Eqs. (42) and (43) can be expressed differently as

$$
M^{c}(t)=\left[\sum_{n=1}^{\infty} \sum_{k=1}^{2} r_{n k}^{M} A_{n k}(t)\right] M_{1}^{1} H
$$

and

$$
\Delta M^{c}(t)=\left[\sum_{n=1}^{\infty} \sum_{i=1}^{2} \Delta r_{n k}^{M} A_{n k}(t)\right] M_{l}^{1} H
$$

Equations (42) and (43) are useful for providing the information about the contribution of each liquid, and Eqs. (44) and (45) are useful for comparing with the results of an identical tank filled with one liquid to assess the effect of two-liquid interaction.

Applying the same analogy that used in obtaining the convective components of the hydrodynamic pressure and base shear for system in rocking from the corresponding results for system excited laterally, one obtains, from Eqs. (42) and (43), the expressions of the convective components of the base moments for system in rocking

$$
\begin{aligned}
M^{c r}(t) & =\left[\sum_{n=1}^{\infty} \sum_{k=1}^{2} \gamma_{n k} C_{n k}^{M I} A_{n k}^{r}(t)\right] M_{11} H_{1} \\
& +\left[\sum_{n=1}^{\infty} \sum_{k=1}^{2} \gamma_{n k} C_{n k}^{M I I} A_{n k}^{r}(t)\right] M_{12} H_{2}
\end{aligned}
$$

and

$$
\Delta M^{c r}(t)=\left[\sum_{n=1}^{\infty} \sum_{k=1}^{2} \gamma_{n k} \Delta C_{n k}^{M} A_{n k}^{i}(t)\right] M_{t 1} H_{1}
$$

or from Eqs. (44) and (45), one obtains 


$$
M^{c r}(t)=\left[\sum_{n=1}^{\infty} \sum_{k=1}^{2} \gamma_{n k} r_{n k}^{M} A_{n k}^{r}(t)\right] M_{1}^{1} H
$$

and

$$
\Delta M^{c r}(t)=\left[\sum_{n=1}^{\infty} \sum_{k=1}^{2} \gamma_{n k} \Delta r_{n k}^{M} A_{n k}^{r}(t)\right] M_{1}^{1} H
$$

\section{G. Surface and Interface Sloshing Displacements}

The surface sloshing wave height, $d^{r}(r, \theta, t)$, of an arbitrary point at the liquid surface may be determined from

$$
\left.p_{2}^{c r}\right|_{z_{2}=H_{2}}=\rho_{2} g d(r, \theta, t)
$$

and the sloshing wave height at the interface of the two liquids, $\eta^{\mathrm{r}}(\mathrm{r}, \theta, \mathrm{t})$, may be determined from

$$
\eta(r, \theta, t)=\frac{1}{\left(\rho_{1}-\rho_{2}\right) g}\left(\left.p_{1}^{\mathrm{cr}}\right|_{z_{1}=H_{1}}-\left.p_{2}^{\mathrm{ct}}\right|_{z_{2}=0}\right)
$$

Substituting $p_{1}^{\text {cr }}$ and $p_{2}^{\text {cr }}$ in Eqs. (50) and (51) by Eqs. (11) and (12), one may obtain the expressions for $d(r, \theta, t)$ and $\eta(r, \theta, t)$, and the expressions for the maximum values of these two functions are obtained by evaluating $d(r, \theta, t)$ and $\eta(r, \theta, t)$ at $r=R$ and $\theta=0$. Alternatively, the expressions for these maximum values may be obtained as follows. If the expressions for computing these maximum values for two liquids tank system excited laterally are given by

$$
d(R, 0, t)=\sum_{n=1}^{\infty} \sum_{k=1}^{2} d_{n k} \frac{A_{n k}(t)}{g} R
$$

and

$$
\eta(R, 0, t)=\sum_{n=1}^{\infty} \sum_{k=1}^{2} \eta_{n k} \frac{A_{n k}(t)}{g} R
$$


their counterparts for the same system in rocking may be expressed as

$$
d^{\prime}(R, 0, t)=\sum_{n=1}^{\infty} \sum_{k=1}^{2} \gamma_{n k} d_{n k} \frac{A_{n k}^{r}(t)}{g} R
$$

and

$$
\eta^{r}(R, 0, t)=\sum_{n=1}^{\infty} \sum_{k=1}^{2} \gamma_{n k} \eta_{n k} \frac{A_{n k}^{r}(t)}{g} R
$$

Once the proportionality factor, $\gamma_{\mathrm{ak}}$, is known, the maximum values of the surface and interface sloshing wave heights may be computed from the corresponding solvtions for liquid-tank system excited laterally by making use of Eqs. (54) and (55).

Now, the generalized Betti's principle stated in Ref. 3 is invoked herein to determine the proportionality factor, $\gamma_{\mathrm{nk}}$. In noting that for a tank subjected to lateral and rocking base motions of the same timewise variations and for each mode of vibration of the sloshing motion in the tank, the work done by the base shear for the tank in rocking through the displacement of the laterally excited tank is equal to the work done by the foundation moment for laterally excited tank acting through the rotation of the tank in rocking, from Eqs. (41), (44) and (45) one obtains

$$
\gamma_{n k} r_{n k}^{\prime}=r_{n k}^{M}+\Delta r_{n k}^{M}
$$

therefore,

$$
\gamma_{n k}=\frac{r_{n k}^{M}+\Delta r_{n k}^{M}}{r_{n k}^{3}}
$$

With $\gamma_{\text {nk }}$ determined, all the convective components of the response quantities for tank in rocking can be calculated. Note that the determination of $\gamma_{\mathrm{nk}}$ from Eq. (57) requires only the results for the laterally excited tank; therefore, there is no need to solve the governing equations and the boundary conditions to obtain the convective components of the response for tank in rocking. However, in this paper, for the purpose of confirming the accuracy, the convective components of the response quantities are also computed from the convective pressure defined by Eqs. (11) and (12) which are obtained by direct solving the governing equations and the 
boundary conditions. The identical numerical results obtained by two approaches confirm the accuracy.

Extensive numerical data for laterally excited tank containing two liquids are available in Ref. 5, and also because all the convective component of the response quantities for tank in rocking can be computed from their counterparts for the laterally excited tank, no numerical results for the convective components of the response are presented herein.

\section{CONCLUSIONS}

The complete solutions for tanks containing two liquids under rocking excitation have been presented. Each dynamic response quantity is expressed as the sum of the impulsive and convective components so that the solutions presented may provide a rational basis for evaluating the effects of tank flexibility and soil-structure interaction. It is found that many response quantities for a tank in rocking may be evaluated from the corresponding response quantities for an identical tank excited laterally; especially, all the convective components of the response quantities can be evaluated by such way.

\section{ACKNOWLEDGMENTS}

This work was performed in the Engineering Mechanics Program of the Reactor Engineering Division of Argonne National Laboratory under the auspices of the U.S. Department of Energy, Contract No. W-31-109-Eng-38. 


\section{REFERENCES}

1. A. S. Veletsos, "Seismic Response and Design of Liquid Storage Tanks." Guidelines for the Seismic Design of Oil and Gas Pipeline Systems, ASCE, New York, NY, pp. 255-370 and pp. 443-461 (1984).

2. A. S. Veletsos and Y. Tang, "Dynamics of Vertically Excited Liquid Storage Tanks," J. Struc. Div., ASCE, Vol. 112, No. 10, pp. 1228-1246 (1986).

3. A. S. Veletsos and Y. Tang, "Rocking Response of Liquid Storage Tanks," J. Engrg. Mech. Div., ASCE, Vol. 113, No. 11, pp. 1774-1792 (1987).

4. Y. Tang, "Dynamic Response of Tank Containing Two Liquids," J. Engrg. Mech. Div., ASCE, Vol. 119, No. 3, pp. 531-548 (1993).

5. Y. Tang and Y. W. Chang, "The Exact Solutions to the Dynamic Response of Tanks Containing Two Liquids," Argonne National Laboratory Report ANL/RE 93/2 (1993).

6. Y. Tang, "Free Vibration Analysis of a Tank Containing Two Liquids," submitted to J. Engrg. «ech. Div., ASCE, for review (1992).

7. A. S. Veletsos and J. Y. Yang, "Earthquake Response of Liquid Storage Tanks," Advances in Civil Engineering Through Engineering Mechanics, Proc. ASCE/EMD Spec. Conf., Raleigh, NC, pp. 1-24 (1977).

8. A. S. Veletsos and Y. Tang, "Soil-Structure Interaction Effects for Laterally Excited Liquid Storage Tanks," J. Earth. Engrg. and Struc. Dyna., Vol. 19, pp. $473-496$ (1989).

9. Y. Tang and Y. W. Chang, "Dynamic Response of a Tank Containing Two Liquids," Argonne National Laboratory Report ANL/RE 92/1 (1992). 
Table I. Quantities in Expressions for the Impulsive Components of Response for $\mathrm{H}_{2} / \mathrm{H}_{1}=0.5$

\begin{tabular}{|c|c|c|c|c|c|}
\hline$\frac{\mathrm{H}}{\mathrm{R}}$ & $\begin{array}{l}S_{0}^{\text {Ir }} \\
(1)\end{array}$ & $\begin{array}{l}S_{\circ}^{\text {IIr }} \\
(2)\end{array}$ & $\begin{array}{l}C_{o M}^{\text {Ir }} \\
(3)\end{array}$ & $\begin{array}{l}C_{o M}^{1 I r} \\
(4)\end{array}$ & $\begin{array}{c}\Delta \mathrm{C}_{\mathrm{o} M}^{\mathrm{r}} \\
(5)\end{array}$ \\
\hline \multicolumn{6}{|c|}{$\alpha=0.25$} \\
\hline $\begin{array}{l}0.3 \\
0.5 \\
1.0 \\
1.5 \\
2.0 \\
2.5 \\
3.0\end{array}$ & $\begin{array}{l}0.396 \\
0.380 \\
0.346 \\
0.324 \\
0.312 \\
0.306 \\
0.303\end{array}$ & $\begin{array}{l}0.200 \\
0.223 \\
0.286 \\
0.358 \\
0.428 \\
0.489 \\
0.540\end{array}$ & $\begin{array}{l}0.149 \\
0.147 \\
0.142 \\
0.143 \\
0.147 \\
0.153 \\
0.159\end{array}$ & $\begin{array}{l}0.470 \\
0.526 \\
0.679 \\
0.851 \\
1.020 \\
1.169 \\
1.292\end{array}$ & $\begin{array}{l}4.561 \\
1.575 \\
0.341 \\
0.130 \\
0.063 \\
0.035 \\
0.021\end{array}$ \\
\hline \multicolumn{6}{|c|}{$\alpha=0.5$} \\
\hline $\begin{array}{l}0.3 \\
0.5 \\
1.0 \\
1.5 \\
2.0 \\
2.5 \\
3.0 \\
\end{array}$ & $\begin{array}{l}0.469 \\
0.447 \\
0.398 \\
0.368 \\
0.352 \\
0.342 \\
0.337 \\
\end{array}$ & $\begin{array}{l}0.193 \\
0.212 \\
0.264 \\
0.326 \\
0.389 \\
0.445 \\
0.493 \\
\end{array}$ & $\begin{array}{l}0.187 \\
0.182 \\
0.172 \\
0.171 \\
0.174 \\
0.179 \\
0.184 \\
\end{array}$ & $\begin{array}{l}0.455 \\
0.500 \\
0.628 \\
0.778 \\
0.930 \\
1.068 \\
1.185 \\
\end{array}$ & $\begin{array}{l}5.037 \\
1.725 \\
0.366 \\
0.137 \\
0.065 \\
0.036 \\
0.021\end{array}$ \\
\hline \multicolumn{6}{|c|}{$\alpha=0.75$} \\
\hline $\begin{array}{l}0.3 \\
0.5 \\
1.0 \\
1.5 \\
2.0 \\
2.5 \\
3.0\end{array}$ & $\begin{array}{l}0.539 \\
0.507 \\
0.441 \\
0.403 \\
0.381 \\
0.369 \\
0.360\end{array}$ & $\begin{array}{l}0.188 \\
0.202 \\
0.246 \\
0.302 \\
0.360 \\
0.413 \\
0.459\end{array}$ & $\begin{array}{l}0.223 \\
0.214 \\
0.197 \\
0.192 \\
0.194 \\
0.198 \\
0.202\end{array}$ & $\begin{array}{l}0.442 \\
0.478 \\
0.587 \\
0.722 \\
0.863 \\
0.994 \\
1.108\end{array}$ & $\begin{array}{l}5.508 \\
1.864 \\
0.387 \\
0.143 \\
0.067 \\
0.036 \\
0.022\end{array}$ \\
\hline \multicolumn{6}{|c|}{$\alpha=1.0$} \\
\hline $\begin{array}{l}0.3 \\
0.5 \\
1.0 \\
1.5 \\
2.0 \\
2.5 \\
3.0 \\
\end{array}$ & $\begin{array}{l}0.605 \\
0.562 \\
0.476 \\
0.430 \\
0.404 \\
0.389 \\
0.378 \\
\end{array}$ & $\begin{array}{l}0.183 \\
0.194 \\
0.232 \\
0.283 \\
0.337 \\
0.388 \\
0.434\end{array}$ & $\begin{array}{l}0.257 \\
0.243 \\
0.217 \\
0.209 \\
0.209 \\
0.212 \\
0.215\end{array}$ & $\begin{array}{l}0.431 \\
0.459 \\
0.553 \\
0.678 \\
0.811 \\
0.937 \\
1.049\end{array}$ & $\begin{array}{l}5.945 \\
1.994 \\
0.404 \\
0.147 \\
0.069 \\
0.037 \\
0.022\end{array}$ \\
\hline
\end{tabular}


Table II. Quantities in Expressions for the Impulsive Components of Response for $\mathrm{H}_{2} / \mathrm{H}_{1}=2$

\begin{tabular}{|c|c|c|c|c|c|}
\hline$\frac{\mathrm{H}}{\mathrm{R}}$ & $S_{0}^{\text {Ir }}$ & $S_{0}^{\text {IIt }}$ & $\mathrm{C}_{\mathrm{oM}}^{\mathrm{It}}$ & $\mathrm{C}_{\mathrm{oM}}^{\mathrm{IIr}}$ & $\Delta C_{0 M}^{r}$ \\
\hline \multicolumn{6}{|c|}{$\alpha=0.25$} \\
\hline $\begin{array}{l}0.3 \\
0.5 \\
1.0 \\
1.5 \\
2.0 \\
2.5 \\
3.0 \\
\end{array}$ & $\begin{array}{l}0.318 \\
0.308 \\
0.281 \\
0.254 \\
0.231 \\
0.212 \\
0.196 \\
\end{array}$ & $\begin{array}{l}0.348 \\
0.358 \\
0.386 \\
0.416 \\
0.445 \\
0.472 \\
0.492 \\
\end{array}$ & $\begin{array}{l}0.134 \\
0.130 \\
0.120 \\
0.111 \\
0.103 \\
0.097 \\
0.093 \\
\end{array}$ & $\begin{array}{l}0.296 \\
0.309 \\
0.342 \\
0.378 \\
0.413 \\
0.445 \\
0.474 \\
\end{array}$ & $\begin{array}{r}12.347 \\
4.356 \\
1.004 \\
0.401 \\
0.200 \\
0.114 \\
0.071 \\
\end{array}$ \\
\hline \multicolumn{6}{|c|}{$\alpha=0.5$} \\
\hline $\begin{array}{l}0.3 \\
0.5 \\
1.0 \\
1.5 \\
2.0 \\
2.5 \\
3.0\end{array}$ & $\begin{array}{l}0.466 \\
0.442 \\
0.383 \\
0.334 \\
0.295 \\
0.264 \\
0.240\end{array}$ & $\begin{array}{l}0.340 \\
0.344 \\
0.361 \\
0.388 \\
0.419 \\
0.448 \\
0.474\end{array}$ & $\begin{array}{l}0.208 \\
0.198 \\
0.174 \\
0.155 \\
0.139 \\
0.128 \\
0.120\end{array}$ & $\begin{array}{l}0.289 \\
0.297 \\
0.322 \\
0.356 \\
0.393 \\
0.427 \\
0.458\end{array}$ & $\begin{array}{r}16.280 \\
5.654 \\
1.247 \\
0.479 \\
0.232 \\
0.129 \\
0.078\end{array}$ \\
\hline \multicolumn{6}{|c|}{$\alpha=0.75$} \\
\hline $\begin{array}{l}0.3 \\
0.5 \\
1.0 \\
1.5 \\
2.0 \\
2.5 \\
3.0 \\
\end{array}$ & $\begin{array}{l}0.606 \\
0.564 \\
0.467 \\
0.395 \\
0.342 \\
0.302 \\
0.272 \\
\end{array}$ & $\begin{array}{l}0.333 \\
0.332 \\
0.341 \\
0.366 \\
0.399 \\
0.431 \\
0.459 \\
\end{array}$ & $\begin{array}{l}0.279 \\
0.260 \\
0.218 \\
0.188 \\
0.166 \\
0.151 \\
0.139 \\
\end{array}$ & $\begin{array}{l}0.284 \\
0.287 \\
0.306 \\
0.339 \\
0.377 \\
0.414 \\
0.447 \\
\end{array}$ & $\begin{array}{r}20.088 \\
6.857 \\
1.448 \\
0.540 \\
0.256 \\
0.140 \\
0.084 \\
\end{array}$ \\
\hline \multicolumn{6}{|c|}{$\alpha=1.0$} \\
\hline $\begin{array}{l}0.3 \\
0.5 \\
1.0 \\
1.5 \\
2.0 \\
2.5 \\
3.0\end{array}$ & $\begin{array}{l}0.741 \\
0.676 \\
0.538 \\
0.444 \\
0.379 \\
0.331 \\
0.296\end{array}$ & $\begin{array}{l}0.326 \\
0.321 \\
0.324 \\
0.349 \\
0.383 \\
0.417 \\
0.447\end{array}$ & $\begin{array}{l}0.347 \\
0.317 \\
0.255 \\
0.214 \\
0.187 \\
0.168 \\
0.154\end{array}$ & $\begin{array}{l}0.278 \\
0.278 \\
0.292 \\
0.325 \\
0.365 \\
0.405 \\
0.439\end{array}$ & $\begin{array}{r}23.778 \\
7.974 \\
1.617 \\
0.588 \\
0.275 \\
0.148 \\
0.088\end{array}$ \\
\hline
\end{tabular}






Fig. 1. System Considered 

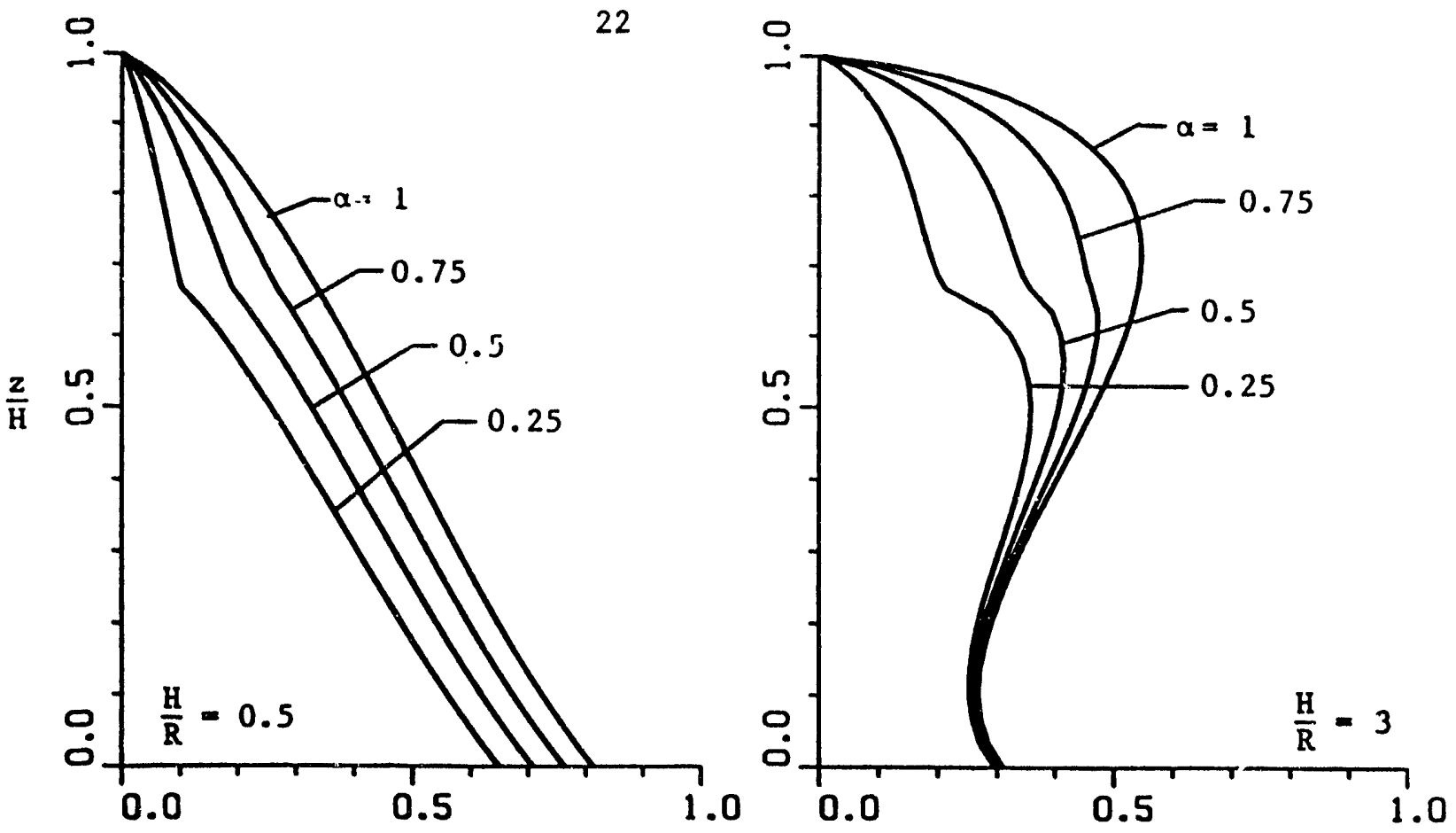

Fig. 2. Impulsive Pressure Exerted on Tank Wall for $\mathrm{H}_{2} / \mathrm{H}_{1}=0.5$
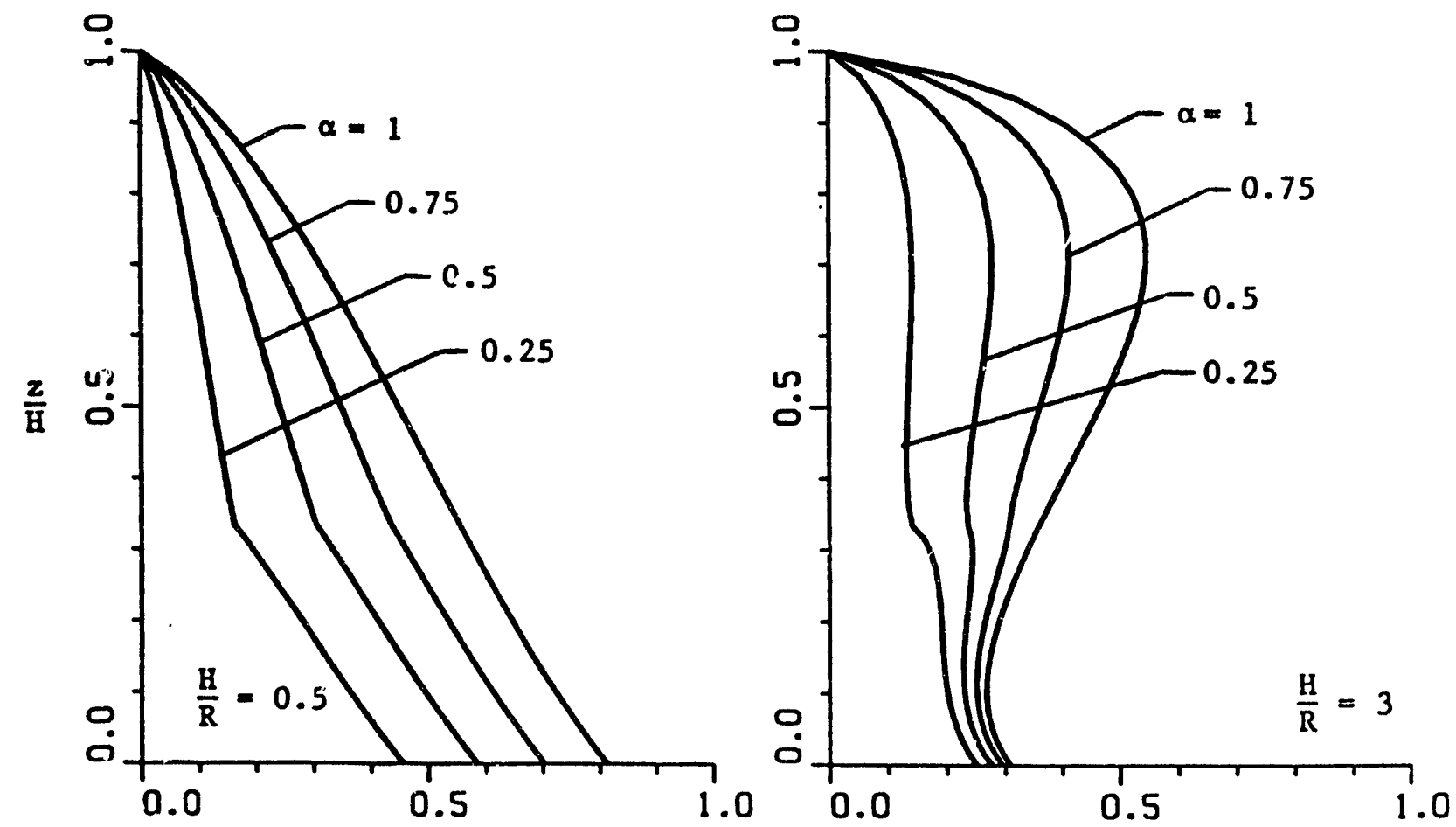

Fig. 3. Impulsive Pressure Exerted on Tank Wall for $\mathrm{H}_{2} / \mathrm{H}_{1}=2$ 

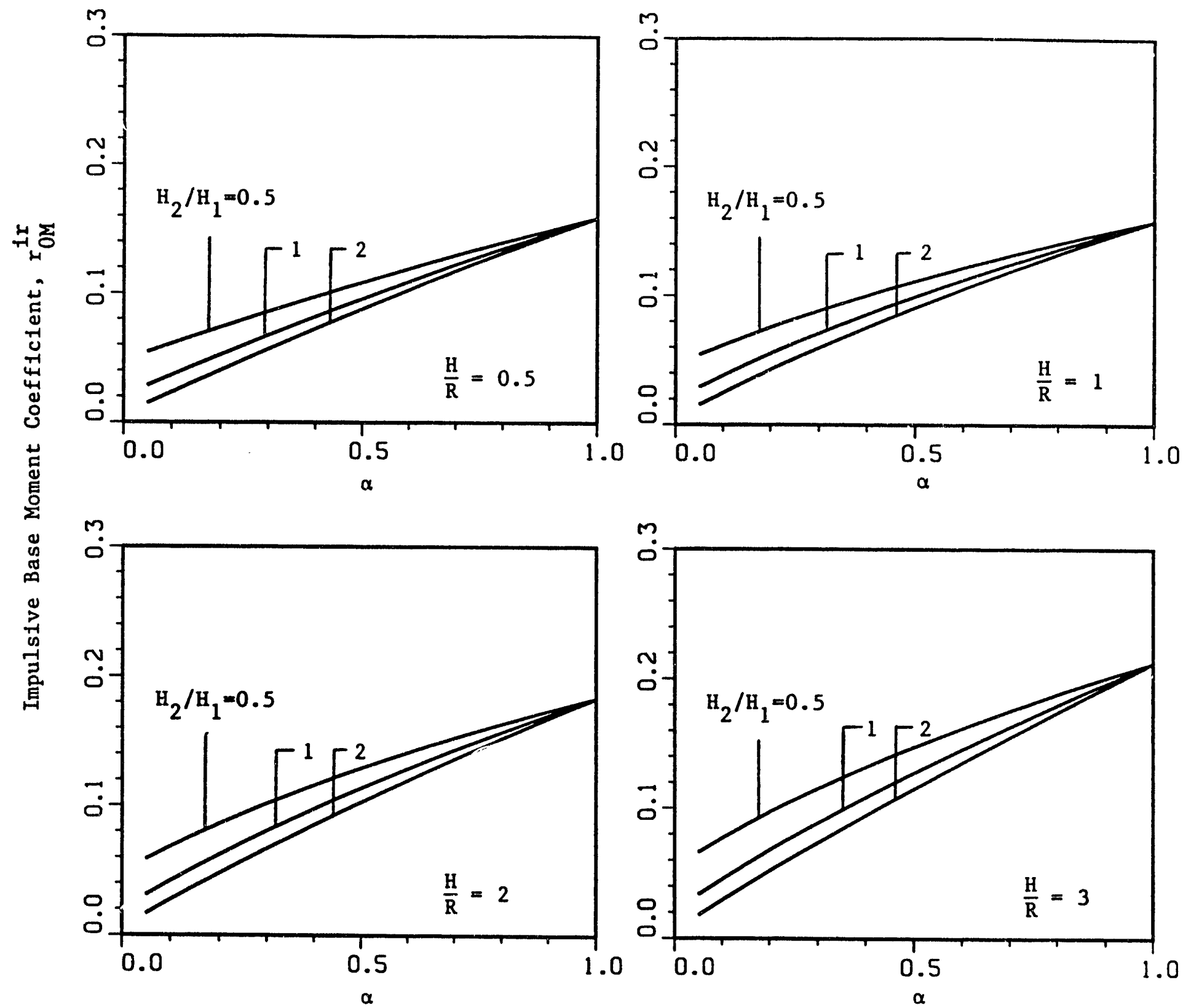

Fig. 4. Effect of Mass Densities on Impulsive Component of Base Moment 

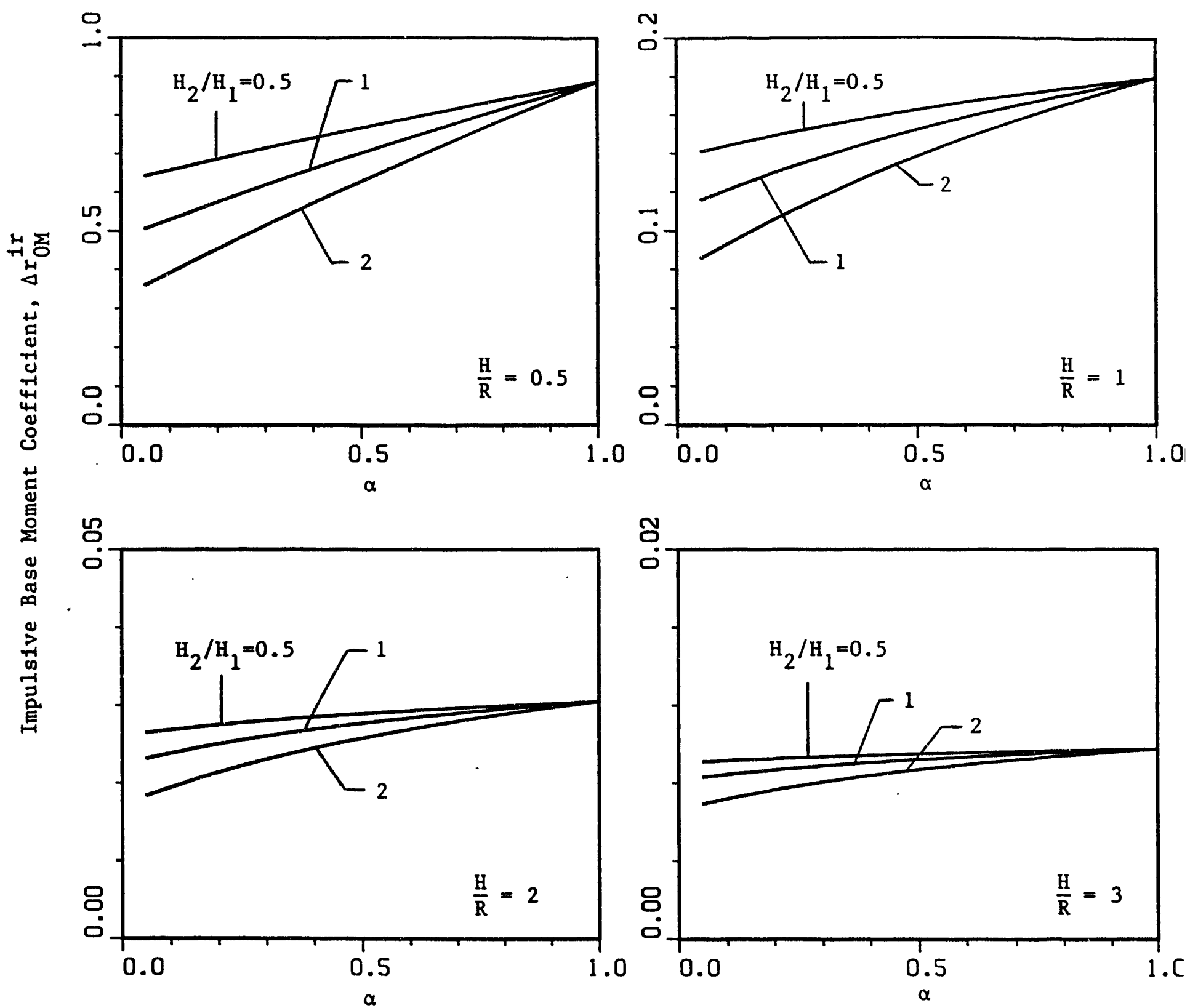

Fig. 5. Effect of Mass Densities on Impulsive Component of Base Moment 


\section{A-1}

\section{APPENDIX A. SOLUTION FOR RIGID TANKS}

\section{A. Impulsive Component of Solution}

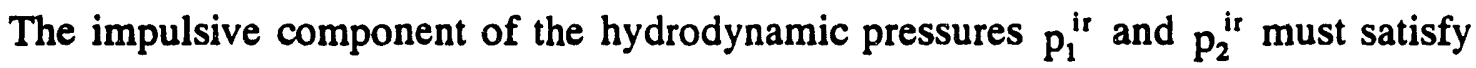

$$
\nabla p_{1}^{\text {ir }}=0
$$

and

$$
\nabla p_{2}^{\text {ir }}=0
$$

and the following boundary conditions:

$$
\begin{aligned}
& -\left.\frac{1}{\rho_{1}} \frac{\partial p_{1}^{i r}}{\partial z_{1}}\right|_{z_{2}=0}=r \ddot{b}_{b}(t) \cos \theta \\
& -\left.\frac{1}{\rho_{1}} \frac{\partial p_{1}^{i r}}{\partial r}\right|_{r=R}=-z_{1} \ddot{\theta}_{b}(t) \cos \theta \\
& -\left.\frac{1}{\rho_{2}} \frac{\partial p_{2}^{i r}}{\partial r}\right|_{r=R}=-\left(z_{2}+H_{1}\right) \ddot{\theta}_{b}(t) \cos \theta \\
& \left.p_{2}^{i r}\right|_{z_{2}=H_{2}}=0 \\
& -\left.\frac{1}{\rho_{1}} \frac{\partial p_{1}^{i r}}{\partial z_{1}}\right|_{z_{1}=H_{1}}=-\left.\frac{1}{\rho_{2}} \frac{\partial p_{2}^{i r}}{\partial z_{2}}\right|_{z_{2}=0} \\
& \left.p_{1}^{i r}\right|_{z_{1}=H_{1}}=\left.p_{2}^{i r}\right|_{z_{2}=0} \\
& p_{1}^{i r} \text { and } p_{2}^{i r} \text { are finite at } r=0
\end{aligned}
$$




\section{A-2}

The method of separation of variables is employed to solve Eqs. (58a) and (58b), and the integration constants are determined from the boundary conditions. Satisfying Eqs. (58a), (59b), and $(59 \mathrm{~g})$, the function $\mathrm{p}_{1}^{\mathrm{ir}}$ takes the form

$$
p_{1}^{i r}=\left[\frac{r}{R} \frac{z_{1}}{H}+\frac{R}{H} \sum_{n=1}^{\infty}\left(A_{n} \cosh \left(\lambda_{n} \frac{z_{1}}{R}\right)+B_{n} \sinh \left(\lambda_{n} \frac{z_{1}}{R}\right)\right) \frac{J_{1}\left(\lambda_{n} \frac{r}{R}\right)}{J_{1}\left(\lambda_{n}\right)}\right] \rho_{1} R \ddot{x}_{T}(t) \cos \theta
$$

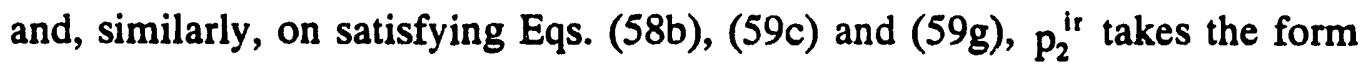

$p_{2}^{i r}=\left[\frac{r}{R} \frac{\left(z_{2}+H_{1}\right)}{H}+\frac{R}{H} \sum_{n=1}^{\infty}\left(C_{n} \cosh \left(\lambda_{n} \frac{z_{2}}{R}\right)+D_{n} \sinh \left(\lambda_{n} \frac{z_{2}}{R}\right)\right) \frac{J_{1}\left(\lambda_{n} \frac{r}{R}\right)}{J_{1}\left(\lambda_{n}\right)}\right] \rho_{2} R \ddot{x}_{T}(t) \cos \theta$

In Eqs. $(60)$ and $(61), \ddot{x}_{T}(t)=H \ddot{\theta}_{b}(t), J_{1}=$ Bessel function of the first kind of order $1, \lambda_{n}=$ the nth zero of $J_{1}^{\prime}(\lambda)$, the first derivative of $J_{1}$; and $A_{n}, B_{n}, C_{n}$ and $D_{n}=$ constants of integration that may be determined from the boundary conditions defined by Eqs. (59a), (59d), (59e) and (59f). After evaluating these constants of integration, and substituting them back into Eqs. (60) and (61), the results are cast into the following forms

$$
p_{1}^{\text {ir }}\left(r, \theta, z_{1}, t\right)=C_{0}^{\text {lr }}\left(r, z_{1}\right) \rho_{1} R \ddot{x}_{T}(t) \cos \theta
$$

and

$$
\mathrm{p}_{2}^{\mathrm{ir}}\left(\mathrm{r}, \theta, \mathrm{z}_{2}, \mathrm{t}\right)=\mathrm{C}_{0}^{\mathrm{IIr}}\left(r, \mathrm{z}_{2}\right) \rho_{2} R \ddot{x}_{T}(\mathrm{t}) \cos \theta
$$

in which $C_{0}^{\mathrm{Ir}}\left(r, z_{1}\right)$ and $C_{0}^{I I r}\left(r, z_{2}\right)=$ dimensionless coefficients given by 
$C_{0}^{\text {Ir }}\left(r, z_{1}\right)=\frac{r}{R} \frac{z_{1}}{H}+\frac{R}{H} \sum_{n=1}^{\infty} \frac{G_{n}}{\Delta_{n}}\left(A_{n} \cosh \left(\lambda_{n} \frac{z_{1}}{R}\right)+B_{n} \sin \left(\lambda_{n} \frac{z_{1}}{R}\right)\right) \cdot \frac{J_{1}\left(\lambda_{n} \frac{r}{R}\right)}{J_{1}\left(\lambda_{n}\right)}$

and

$$
\begin{aligned}
C_{0}^{\text {IIr }}\left(r, z_{2}\right) & =\frac{r}{R} \frac{\left(z_{2}+H_{1}\right)}{H}+\frac{R}{H} \sum_{n=1}^{\infty} \frac{G_{n}}{\Delta_{n}}\left(C_{n} \cosh \left(\lambda_{n} \frac{z_{2}}{R}\right)\right. \\
& \left.+D_{n} \sin \left(\lambda_{n} \frac{z_{2}}{R}\right)\right) \frac{J_{1}\left(\lambda_{n} \frac{r}{R}\right)}{J_{1}\left(\lambda_{n}\right)}
\end{aligned}
$$

where

$$
\begin{aligned}
A_{n} & =\frac{2}{\lambda_{n}}\left(\sinh \beta_{1 \mathrm{n}} \cosh \beta_{2 \mathrm{n}}+\alpha \cosh \beta_{2 \mathrm{n}} \sinh \beta_{2 \mathrm{n}}\right) \\
& +(\alpha-1) \frac{H_{1}}{\mathrm{r}} \cosh \beta_{2 \mathrm{i}}-\frac{\mathrm{H}}{\mathrm{R}} \alpha \\
\mathrm{B}_{\mathrm{n}} & =-\frac{2}{\lambda_{\mathrm{n}}}\left(\cosh \beta_{1 \mathrm{n}} \cosh \beta_{2 \mathrm{n}}+\alpha \sinh \beta_{1 \mathrm{n}} \sinh \beta_{2 \mathrm{n}}\right) \\
\mathrm{C}_{\mathrm{n}} & =\frac{2}{\lambda_{\mathrm{n}}} \sinh \beta_{2 \mathrm{n}}-\frac{\mathrm{H}}{\mathrm{R}} \cosh \beta_{1 \mathrm{n}}+(1-\alpha) \frac{H_{1}}{\mathrm{R}} \sinh \beta_{1 \mathrm{n}} \cosh \beta_{2 \mathrm{n}} \\
D_{\mathrm{n}} & =-\frac{2}{\lambda_{\mathrm{n}}} \cosh \beta_{2 \mathrm{n}}+(\alpha-1) \frac{H_{1}}{\mathrm{R}} \sinh \beta_{1 \mathrm{n}} \cosh \beta_{2 \mathrm{n}}-\frac{H}{\mathrm{R}} \alpha \sinh \beta_{1 \mathrm{n}} \\
G_{\mathrm{n}} & =\frac{2}{\lambda_{\mathrm{n}}^{2}-1}
\end{aligned}
$$




\section{A-4}

$\Delta_{\mathrm{n}}=\cosh \beta_{1 \mathrm{n}} \cosh \beta_{2 \mathrm{a}}+\alpha \sinh \beta_{1 \mathrm{n}} \sinh \beta_{2 \mathrm{a}}$

\section{B. Convective Component of Solution}

The convective component of the hydrodynamic pressures $p_{1}^{\text {cr }}$ and $p_{2}^{\text {cr }}$ must satisfy Laplace's equations

$$
\nabla^{2} p_{1}^{\text {cr }}=0
$$

and

$$
\nabla^{2} p_{2}^{\text {cr }}=0
$$

along with the boundary conditions

$$
\begin{aligned}
& \left.\frac{\partial p_{1}^{c r}}{\partial z_{1}}\right|_{z_{1}=0}=0 \\
& -\left.\frac{1}{\rho_{1}} \frac{\partial p_{1}^{c r}}{\partial r}\right|_{r=R}=0 \\
& -\left.\frac{1}{\rho_{2}} \frac{\partial p_{2}^{c r}}{\partial r}\right|_{r=R}=0 \\
& \left.\left(\frac{\partial^{2} p_{2}^{c r}}{\partial t^{2}}+g \frac{\partial p_{2}^{c r}}{\partial z_{2}}\right)\right|_{z_{2}=H_{2}}=-\left.g \frac{\partial p_{2}^{i r}}{\partial z_{2}}\right|_{z_{2}=H_{2}} \\
& -\left.\frac{1}{\rho_{1}} \frac{\partial p_{1}^{c r}}{\partial z_{1}}\right|_{z_{1}=H_{1}}=-\left.\frac{1}{\rho_{2}} \frac{\partial p_{2}^{c r}}{\partial z_{2}}\right|_{z_{2}=0} \\
& \left.\left(\frac{\partial p_{1}^{c r}}{\partial t^{2}}+g \frac{\partial p_{1}^{c r}}{\partial z_{1}}+g \frac{\partial p_{1}^{i r}}{\partial z_{1}}\right)\right|_{z_{1}=H_{1}}
\end{aligned}
$$




\section{A-5}

$$
=\left.\left(\frac{\partial p_{2}^{c r}}{\partial t^{2}}+g \frac{\partial p_{2}^{c r}}{\Delta z_{2}}+g \frac{\partial p_{2}^{i r}}{\partial z_{2}}\right)\right|_{z_{2}=0}
$$

$\mathrm{p}_{1}^{\mathrm{cr}}$ and $\mathrm{p}_{2}^{\mathrm{cr}}$ are finite at $\mathrm{r}=0$.

Again, the method of separation of variables is employed to solve Eqs. (67a) and (67b), and the integration constants are determined from the boundary conditions. Satisfying Eqs. (67a), (67b), (68a), (68b), (68c), (68e) and (68g), the function $\mathrm{p}_{1}^{\text {er }}$ takes the form

$$
p_{1}^{c r}\left(r, 0, z_{1}, t\right)=\left[\sum_{n=1}^{\infty} D_{n}(t) \cosh \left(\lambda_{n} \frac{z_{1}}{R}\right) \frac{J_{1}\left(\lambda_{n} \frac{r}{R}\right)}{J_{1}\left(\lambda_{n}\right)}\right] \rho_{1} R \cos \theta
$$

and $\mathrm{p}_{2}^{\text {cr }}$ takes the form

$$
\begin{aligned}
p_{2}^{c r}\left(r, \theta, z_{2}, t\right) & =\left[\sum_{n=1}^{\infty}\left(E_{n}(t) \cosh \left(\lambda_{n} \frac{z_{2}}{R}\right)+D_{n}(t) \sinh \beta_{1 n} \sinh \left(\lambda_{n} \frac{z_{2}}{R}\right)\right)\right. \\
& \left.\frac{J_{1}\left(\lambda_{n} \frac{r}{R}\right)}{J_{1}\left(\lambda_{n}\right)}\right] \rho_{2} R \cos \theta
\end{aligned}
$$

in which $E_{n}(t)$ and $F_{n}(t)=$ integration functions that can be determined by satisfying Eqs. (68d) and (68f). Substituting Eqs. (62), (63), (69a) and (69b) into Eq. (68d), one obtains a differential equation 


$$
\begin{aligned}
\sinh \beta_{1 \mathrm{n}} & \sinh \beta_{2 \mathrm{n}} \ddot{E}_{\mathrm{n}}+\frac{g \lambda_{\mathrm{n}}}{\mathrm{R}} \sinh \beta_{1 \mathrm{n}} \cosh \beta_{2 \mathrm{n}} \mathrm{E}_{\mathrm{n}}+\cosh \beta_{2 \mathrm{n}} \ddot{F}_{\mathrm{n}} \\
+ & \frac{g \lambda_{\mathrm{n}}}{\mathrm{R}} \sinh \beta_{2 \mathrm{n}} \mathrm{F}_{\mathrm{n}}=\frac{-g \lambda_{\mathrm{n}}}{\mathrm{R}} \frac{\mathrm{R}}{\mathrm{H}} \frac{G_{\mathrm{n}}}{\Delta_{\mathrm{n}}}\left(\frac{\Delta_{\mathrm{n}}}{\lambda_{\mathrm{n}}}+C_{\mathrm{n}} \sinh \beta_{2 \mathrm{n}}+D_{\mathrm{n}} \cosh \beta_{2 \mathrm{n}}\right) \ddot{x}_{\mathrm{T}}(\mathrm{t})
\end{aligned}
$$

and substituting Eqs. (63) and (69b) into Eq. (68f), one obtains another differential equation

$$
\begin{aligned}
\cosh \beta_{1 n} \ddot{E}_{n}+(1-\alpha) \frac{g \lambda_{n}}{R} \sinh \beta_{1 n} E_{n}-\alpha \ddot{F}_{n} \\
=-\frac{g \lambda_{n}}{R} \frac{R}{H} \cdot \frac{G}{\Delta_{n}}\left[(1-\alpha) \frac{\Delta_{n}}{\lambda_{n}}+A_{n} \sinh \beta_{1 n}+B_{n} \cosh \beta_{1 n}-\alpha D_{n}\right] \ddot{x}_{T}(t)
\end{aligned}
$$

then, Eqs. (70) and (71) can be solved for $E_{n}(t)$ and $F_{n}(t)$.

Taking the Laplace transformation on both sides of Eqs. (70) and (71) and assuming the homogeneous initial conditions for $E_{n}(t)$ and $F_{n}(t)$, one obtains two algebraic equations for determination of the Laplace transforms of $E_{n}(t)$ and $F_{n}(t)$. The required solutions for $E_{n}(t)$ and $F_{n}(t)$ are then obtained by finding the inverse Laplace transforms; then replacing $E_{n}(t)$ and $F_{n}(t)$ in Eqs. (69a) and (69b) with the results obtained, one can cast the final expressions into the form presented in Eqs. (11) and (12). The derivation is not difficult but tedious; hence, it is omitted herein. However, the details of the derivation are available in Ref. 5.

The expressions for $C_{n k}^{\text {Ir }}\left(r, z_{1}\right)$ and $C_{n k}^{\text {IIr }}\left(r, z_{2}\right)$ for $k=1$ and 2 are given as follows.

$$
\begin{aligned}
& C_{n 1}^{\text {Ir }}\left(r, z_{1}\right)=-\frac{G_{n}}{\Delta_{n}} \frac{1}{\Lambda_{n 1}} x_{1} \cosh \left(\lambda_{n} \frac{z_{1}}{R}\right) \frac{J_{1}\left(\lambda_{n} \frac{r}{R}\right)}{J_{1}\left(\lambda_{n}\right)} \\
& C_{n 2}^{\text {If }}\left(r, z_{1}\right)=\frac{-G_{n}}{\Delta_{n}} \cdot \frac{1}{\Lambda_{n 2}} y_{1} \cosh \left(\lambda_{n} \frac{z_{1}}{R}\right) \frac{J_{1}\left(\lambda_{n} \frac{r}{R}\right)}{J_{1}\left(\lambda_{n}\right)}
\end{aligned}
$$




$$
\begin{aligned}
C_{n 1}^{\text {IIr }}\left(r, z_{2}\right)= & -\frac{G_{n}}{\Delta_{n}} \cdot \frac{1}{\Lambda_{n 1}}\left[x_{2} \cosh \left(\lambda_{n} \frac{z_{2}}{R}\right)+x_{1} \sinh \beta_{1 n} \sin \left(\lambda_{n} \frac{z_{2}}{R}\right)\right] \\
& \frac{J_{1}\left(\lambda_{n} \frac{r}{R}\right)}{J_{1}\left(\lambda_{n}\right)} \\
C_{n 2}^{\text {IIr }}\left(r, z_{2}\right)= & -\frac{G_{n}}{\Delta_{n}} \cdot \frac{1}{\Lambda_{n 2}}\left[y_{2} \cosh \left(\lambda_{n} \frac{z_{2}}{R}\right)+y_{1} \sinh \beta_{1 n} \sin \left(\lambda_{n} \frac{z_{2}}{R}\right)\right] \\
& \frac{J_{1}\left(\lambda_{n} \frac{r}{R}\right)}{J_{1}\left(\lambda_{n}\right)}
\end{aligned}
$$

where

$$
\begin{aligned}
& x_{1}=\frac{\Lambda_{n 1} q_{1}-q_{2}}{\Lambda_{n 1}-\Lambda_{n 2}} \\
& y_{1}=\frac{q_{2}-\Lambda_{n 2} q_{1}}{\Lambda_{n 1}-\Lambda_{n 2}} \\
& x_{2}=\frac{\Lambda_{n 1} q_{3}-q_{4}}{\Lambda_{n 1}-\Lambda_{n 2}}
\end{aligned}
$$

and

$$
y_{2}=\frac{q_{4}-\Lambda_{n 2} q_{3}}{\Lambda_{n 1}-\Lambda_{n 2}}
$$

in which

$$
q_{1}=\frac{s_{1} \cosh \beta_{2 n}+\alpha s_{2}}{\Delta_{n}}
$$


$q_{2}=\frac{s_{1} \sinh \beta_{2 n}}{\Delta_{n}}$

$q_{3}=\frac{s_{2} \cosh \beta_{1 n}-s_{1} \sinh \beta_{1 n} \sinh \beta_{2 n}}{\Delta_{n}}$

$q_{4}=\frac{s_{2}(1-\alpha) \sinh \beta_{1 \mathrm{n}}-s_{1} \sinh \beta_{1 \mathrm{n}} \cosh \beta_{2 \mathrm{n}}}{\Delta_{\mathrm{n}}}$

and

$$
\begin{aligned}
& s_{1}=(1-\alpha) \frac{\Delta_{n}}{\lambda_{n}}+A_{n} \sinh \beta_{1 n}+B_{n} \cosh \beta_{1 n}-\alpha D_{n} \\
& s_{2}=\frac{\Delta_{n}}{\lambda_{n}}+C_{n} \sinh \beta_{2 n}+D_{n} \cosh \beta_{2 n}
\end{aligned}
$$

The characteristic equation for the natural frequencies can be obtained from the associated eigenvalue problem of Eqs. (70) and (71). Letting $\ddot{x}_{T}(t)=0$ and $E_{n}(t)=E_{n} e^{i w t}, F_{n}(t)=F_{n} e^{i w t}$ in Eqs. (68) and (69), one obtains two homogeneous equations which are expressed by

$$
\begin{aligned}
& -\omega^{2}\left[\begin{array}{cc}
\sinh \beta_{1 \mathrm{n}} \sinh \beta_{2 \mathrm{n}} & \cosh \beta_{2 \mathrm{n}} \\
\cosh \beta_{1 \mathrm{n}} & -\alpha
\end{array}\right]\left\{\begin{array}{l}
E_{\mathrm{n}} \\
F_{n}
\end{array}\right\} \\
& +\frac{g \lambda_{\mathrm{n}}}{R}\left[\begin{array}{cc}
\sinh \beta_{1 \mathrm{n}} \cosh \beta_{2 \mathrm{n}} & \sinh \beta_{2 \mathrm{n}} \\
(1-\alpha) \sinh \beta_{1 \mathrm{n}} & 0
\end{array}\right]\left\{\begin{array}{l}
E_{n} \\
F_{n}
\end{array}\right\}=0
\end{aligned}
$$

It is easy to show that the determinant of Eq. (77) is Eq. (15), the characteristic equation. 

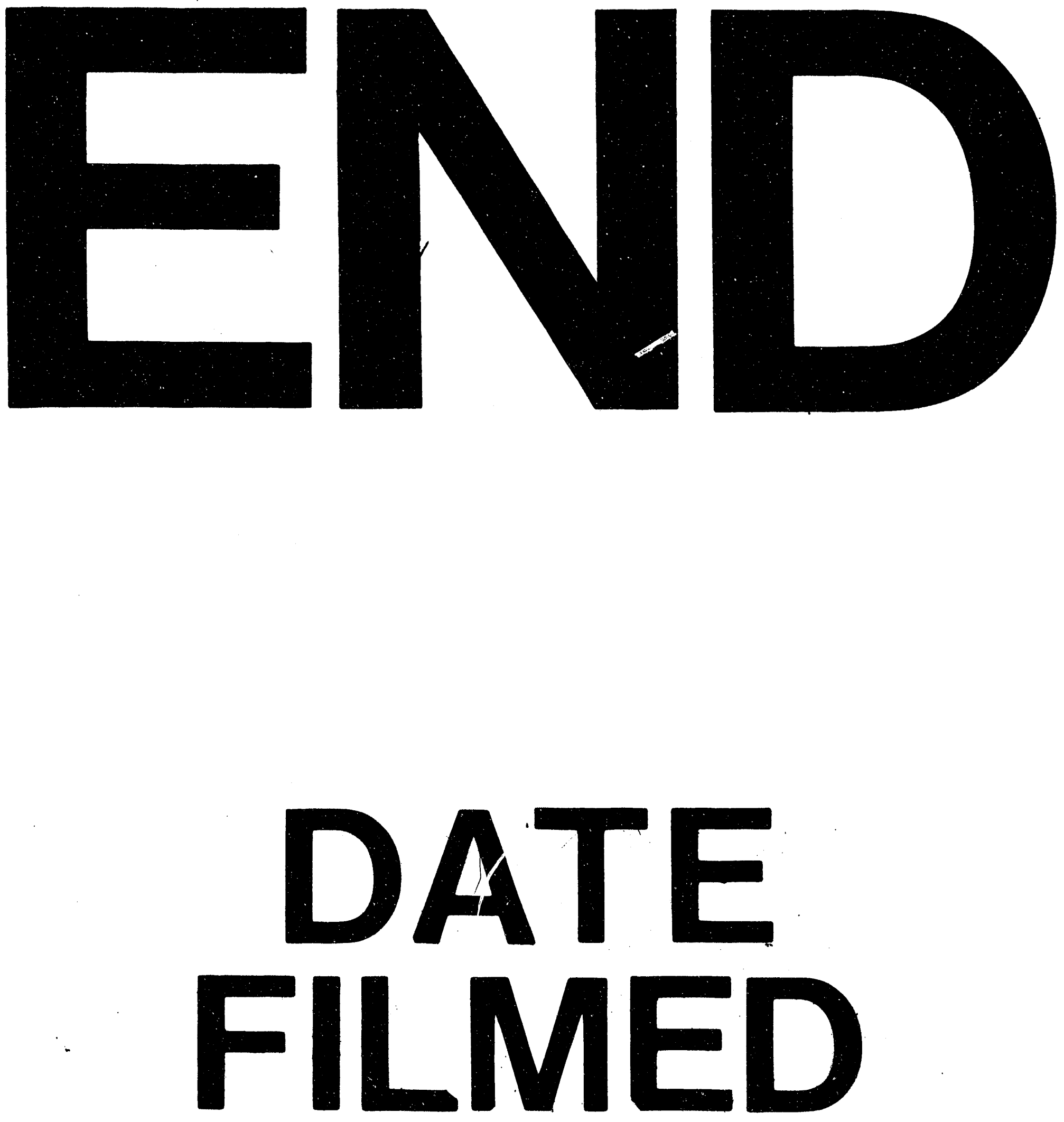

1

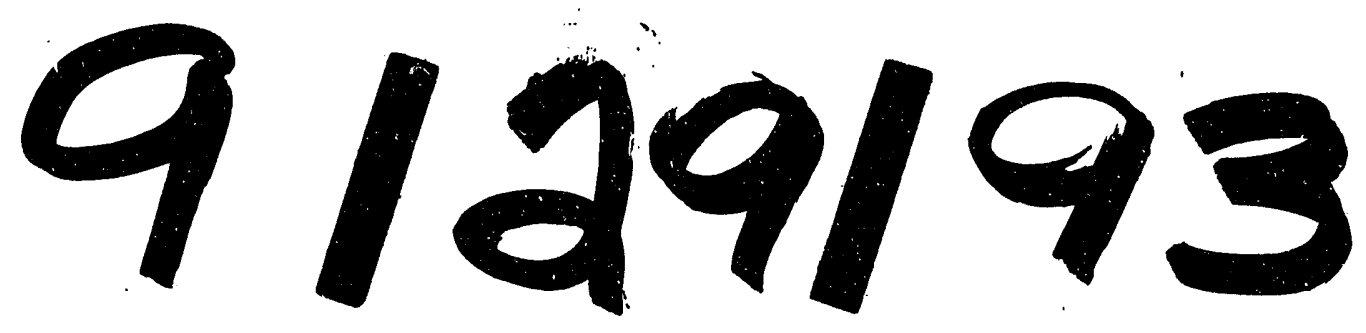


